\title{
ELEVATED CIRCULATING S100A12 ASSOCIATES WITH VASCULAR DISEASE AND WORSE CLINICAL OUTCOME IN PERITONEAL DIALYSIS PATIENTS
}

\author{
Naohito Isoyama, ${ }^{1,2}$ Anna Machowska, ${ }^{1,3}$ Abdul Rashid Qureshi, ${ }^{1}$ Tae Yamamoto, ${ }^{4}$ Björn Anderstam, ${ }^{1}$ \\ Olof Heimburger, ${ }^{1}$ Peter Barany, ${ }^{1}$ Peter Stenvinkel, ${ }^{1}$ and Bengt Lindholm ${ }^{1}$
}

\author{
Divisions of Renal Medicine and Baxter Novum, ${ }^{1}$ Karolinska Institutet, Stockholm, Sweden; Department of Urology, ${ }^{2}$ \\ Yamaguchi University, Ube, Yamaguchi, Japan; Baxter Healthcare Corporation Europe, ${ }^{3}$ and \\ Division of Nephrology, Endocrinology and Vascular Medicine, ${ }^{4}$ Tohoku University \\ Graduate School of Medicine, Sendai, Japan
}

\begin{abstract}
- Background: The pro-inflammatory receptor of advanced glycation end-products (RAGE)-ligand S100A12 is thought to promote, whereas anti-inflammatory soluble RAGE (sRAGE) may protect against, vascular disease. We evaluated circulating S100A12 and sRAGE in relation to vascular disease, inflammation, nutritional status, and mortality risk in peritoneal dialysis (PD) patients.

- Methods: Plasma S100A12 and sRAGE, biomarkers of inflammation, nutritional status, and comorbidities were analyzed in 82 prevalent PD patients (median age 65 years; $70 \%$ men; median vintage 12 months) and, for comparative analysis, also in 190 hemodialysis (HD) patients and 50 control subjects. Associations between mortality risk and concentrations of S100A12 and sRAGE were assessed in PD and HD patients after a mean follow-up period of 31 and 29 months respectively using a competing risk Cox regression model.
\end{abstract}

- Results: In PD patients, median S100A12, sRAGE and S100A12/ sRAGE were markedly higher than in controls, and S100A12 was 1.9 times higher and median sRAGE $14 \%$ lower compared with HD patients. In PD patients, S100A12 associated with C-reactive protein $(\rho=0.46 ; p<0.001)$ and interleukin- $6(\rho=0.38 ; p<$ $0.001)$, and, negatively, with s-albumin $(\rho=-0.27 ; p<0.05)$ whereas sRAGE associated negatively with body mass index ( $\rho=$ $-0.37 ; p<0.001)$, fat body mass index $(\rho=-0.34 ; p<0.001)$, and lean body mass index $(\rho=-0.36 ; p<0.001)$. Peripheral vascular disease or cerebrovascular disease (PCVD) was present in $28 \%$ of $P D$ patients and, in multivariate analysis, associated mainly with high S100A12 (odds ratio [OR] 3.52, $p=0.04$ ). In both PD and HD patients, the highest versus other tertiles of S100A12 associated with increased mortality. In contrast, sRAGE did not associate with PCVD or mortality in PD and HD patients.

- Conclusions: Plasma S100A12 and sRAGE are markedly elevated in PD patients. Soluble RAGE was inversely related to body mass indices while S100A12 associated with increased inflammation, PCVD, and mortality, suggesting that S100A12 may identify PD patients at high risk for vascular disease and increased mortality.

Perit Dial Int 2016; 36(3):269-276 epub ahead of print: 22 0ct 2015 http://dx.doi.org/10.3747/pdi.2014.00121

Correspondence to: Bengt Lindholm, Divisions of Renal Medicine and Baxter Novum, Karolinska Institutet, M99 Karolinska University Hospital Huddinge, S-141 86 Stockholm, Sweden.

Bengt.Lindholm@ki.se

Received 8 May 2014; accepted 1st March 2015.
KEY WORDS: End-stage renal disease; advanced glycation end-products (AGE); receptor of AGE (RAGE); soluble RAGE; inflammation; cardiovascular disease; all-cause mortality.

Cardiovascular disease (CVD) in chronic kidney disease (CKD) Cis linked to inflammation, oxidative stress, and endothelial dysfunction (1,2), and to the advanced glycation end-products (AGE)-receptor of AGE (RAGE) system including RAGE-ligand S100A12 and soluble RAGE (sRAGE) (3). The receptor of AGE expressed on cell surfaces binds with circulating AGEs, S100A12, and other RAGE-ligands, acting as a multi-ligand pattern-recognition receptor mediating pro-inflammatory signals (3). The receptor of AGE is up-regulated in diabetes and CKD, and RAGE-mediated inflammation has been implicated in obesity, insulin resistance, and vascular diseases $(4,5)$.

S100A12 is expressed on cell surfaces of macrophages, lymphocytes, and endothelial cells at sites of local inflammation, where it participates in the AGE-RAGE inflammatory response by inducing production and release of pro-inflammatory cytokines such as interleukin-1 and tumor necrosis factor that may promote atherosclerosis (6).

Soluble RAGE is shed from cellular membranes into circulation and acts as a decoy receptor that neutralizes AGEs and other circulating RAGE-ligands, thereby antagonizing intracellular RAGE signaling and alleviating the pro-inflammatory effects of these ligands (7). In chronic inflammatory conditions such as CVD, sRAGE levels are low, while high levels of endogenous secretory RAGE are thought to be anti-inflammatory and protective against atherosclerotic CVD (8).

Whereas in pro-inflammatory conditions, high plasma S100A12 and low plasma sRAGE associate with increased CVD risk (9), results in CKD are less consistent $(6,10-17)$. In CKD stage- 5 patients starting on dialysis (17) as well as in prevalent hemodialysis (HD) patients (18), S100A12 and sRAGE are markedly elevated, but only S100A12, and not sRAGE, associates with inflammation and mortality. In one study in HD patients, a 2-fold increase of S100A12 was, however, not associated with mortality despite its correlation with inflammation (11).

In peritoneal dialysis (PD) patients, heat sterilization of glucose-based PD fluid could lead to accelerated AGE formation

This single copy is for your personal, non-commercial use only.

For permission to reprint multiple copies or to order presentation-ready

copies for distribution, contact Multimed Inc. at marketing@multi-med.com 
and over-expression of RAGE. In PD patients with 2- to 3-fold higher plasma concentrations of S100A12 than healthy controls, S100A12 associated with carotid atherosclerosis (15) and, in another study, with a high peritoneal solute transport rate (16). However, the mortality-predictive role of S100A12 and sRAGE among PD patients is not known.

In the current study, we evaluated S100A12 and SRAGE in relation to inflammation, nutritional status, comorbidities including presence of vascular disease, and mortality risk in 82 prevalent PD patients. We included for comparative analysis 190 prevalent HD patients who underwent a similar protocol, and 50 community-dwelling controls.

\section{METHODS}

\section{PATIENTS AND STUDY DESIGN}

Patient characteristics are presented in Table 1. The PD cohort consisted of patients from a cross-sectional study on variation in inflammatory markers in prevalent PD patients at the Karolinska University Hospital, Stockholm, Sweden. Among 97 eligible patients, 13 patients did not start the study due to transfer to HD, transplantation, and mortality, and S100A12 or sRAGE could not be measured in 2 patients because stored serum was lacking. Thus, the current study comprised 82 patients with a median age of 65 years, $70 \%$ men, and median dialysis vintage time of 12 (interquartile range [IQR] 6 - 29) months.

Peritoneal dialysis was provided as continuous ambulatory PD ( $77 \%$ of the patients) or automated PD (23\%) using, for the short dwells, biocompatible glucose-based solutions including Physioneal (Baxter Healthcare, Castlebar, Ireland), Gambrosol Trio (Gambro Lundia AB, Lund, Sweden), or BicaVera (Fresenius Medical Care, Bad Homburg, Germany), and, in some patients, amino-acid based solution (Nutrineal, Baxter Healthcare, Castlebar, Ireland), while for the long dwell, a majority of the patients used icodextrin-based solution (Extraneal, Baxter Healthcare, Castlebar, Ireland). The median urine volume was 950 (IQR 500 - 1300) mL, and mean glomerular filtration rate (GFR) calculated as the average of renal creatinine and urea clearance from 24 hours' urine collection was $2.9 \pm 2.2 \mathrm{~mL} /$ $\mathrm{min} / 1.73 \mathrm{~m}^{2}$, while median total (renal plus peritoneal) weekly Kt/V was 2.2 (IQR 1.8 - 2.5). A standard peritoneal equilibration test was performed according to the method of Twardowski.

Comorbidities were assessed based on medical records and included diabetes mellitus (DM) in 20 (24\%) patients, and CVD, defined as cardiac, cerebrovascular (including stroke), or peripheral vascular disease, in $24(29 \%)$ patients. The patients received medications such as phosphate binders and other drugs as indicated clinically; 79 (96\%) patients were on antihypertensive medications. Survival was recorded from the day of examination with a follow-up time of up to 5 years.

\section{COMPARATIVE ANALYSES OF HD PATIENTS AND CONTROL SUBJECTS}

In addition, for comparative analysis, S100A12 and SRAGE were also measured in 190 prevalent HD patients (106 men, median age of 67 [IQR 51 - 74] years), most of whom were included in a previous study from our group (18), and in 50 community-dwelling control subjects (31 men, median age of 63 [IQR 58 - 70] years, median GFR of 82 [IQR $76-91$ ] mL/ $\mathrm{min} / 1.73 \mathrm{~m}^{2}$ ) randomly selected by Statistics Sweden (www. scb.se) among individuals in the Stockholm region. The HD patients and control subjects underwent similar measurements to those of the PD patients.

The local ethics committee of Karolinska Institutet at Karolinska University Hospital Huddinge approved the study, which was conducted in adherence to the Declaration of Helsinki, and informed consent was obtained from each individual.

\section{NUTRITIONAL STATUS}

Body mass index (BMI) was defined as body weight in kilograms divided by square of patient height in meters. In PD patients and controls, body composition was assessed by dual energy x-ray absorptiometry (DEXA; Lunar Corp., Madison, WI, USA) estimating lean body mass (LBM) and fat body mass (FBM). In HD patients, FBM and LBM were assessed according to Durnin et al. (19) from biceps, triceps, subscapular, and suprailiac skinfold thickness measurements with skinfold caliper (Cambridge Scientific Instruments, Cambridge, MD, USA); LBM (LBMI) and FBM (FBMI) indices were calculated according to Kyle et al. (20) and expressed as $\mathrm{kg} / \mathrm{m}^{2}$. Overall protein-energy wasting (PEW) was graded by subjective global assessment (SGA) including 6 subjective assessments: 3 based on patient's history of weight loss, incidence of anorexia, and incidence of vomiting, and 3 based on subjective grading of muscle wasting, edema, and loss of subcutaneous fat. Each patient was given a score reflecting nutritional status: 1 = normal nutritional status, 2 = mild PEW, 3 = moderate PEW, and 4 = severe PEW; PEW was defined as SGA score $>1$ (21).

\section{EVALUATION OF PERIPHERAL OR CEREBROVASCULAR DISEASE AMONG PD AND HD PATIENTS}

Peripheral vascular disease, defined as presence of arterial insufficiency of the extremities, carotid or renal artery stenosis, or aortic aneurysm, and cerebrovascular disease, defined as presence of stroke, transient ischemic attack, subdural hematoma, and intracerebral or sub-arachnoid hemorrhage (22) was recorded and combined into one category, peripheral vascular disease or cerebrovascular disease, or both, PVCD.

\section{BLOOD SAMPLING AND LABORATORY ANALYSIS}

After an overnight fast, plasma samples were taken and stored at $-80^{\circ} \mathrm{C}$, if not analyzed immediately. Plasma concentrations of sRAGE (Human RAGE Quantikine ELISA; R\&D Systems, Inc., Minneapolis, MN, USA), S100A12 (Circulex S100A12/EN-RAGE ELISA kit; Cyclex Co., Ltd., Nagano, Japan), and Ne-(Carboxymethyl)lysine (CML; Cyclex Co., Ltd., Nagano, Japan) were measured using ELISA according to the 
manufacturer's instructions. Interleukin-6 (IL-6) was quantified by immunometric assay on an Immulite Analyzer (Siemens Medical Solution Diagnostics, Los Angeles, CA, USA) according to the manufacturer's instructions. Advanced oxidation protein products (AOPP) were analyzed by a modified assay (23), correcting for impact of serum triglycerides to yield modified AOPP (mAOPP). Circulating albumin, creatinine, total cholesterol, and C-reactive protein (CRP) were analyzed using certified methods at the Department of Clinical Chemistry, Karolinska University Hospital Huddinge.

\section{STATISTICAL ANALYSES}

Data are expressed as mean \pm standard deviation (SD) or median (range of $25^{\text {th }}$ to $75^{\text {th }}$ percentile) or percentage, as appropriate. Statistical significance was set at the level of $p<0.05$. Comparisons between 2 groups were assessed with nonparametric Wilcoxon test for continuous variables and a $\chi^{2}$ test for nominal variables. Differences among 3 groups were analyzed using nonparametric ANOVA Kruskal-Wallis test. Spearman rank correlation analysis was used to determine associations between S100A12 and sRAGE with selected parameters. Multivariate logistic regression analyses were used to assess determinants of existing PVCD with data expressed as $\mathrm{OR}$ and $95 \%$ confidence interval (CI). A competing risk
Cox regression model was used to analyze the independent risk of 2 events-renal transplantation or death. If a patient received renal transplantation, then the outcome of mortality was censored. The functional form of the covariates was evaluated with the use of Martingale residuals. We tested the proportionality of hazards assumption using the Schoenfield residuals. A Cox model with a data augmentation method was used (24) to analyze the competing risks. The 2 types of events were evaluated to see if they had a constant hazard ratio. Covariates were interacted with the outcome to analyze the independent effect of covariates on each of 2 competing endpoints. The cumulative incidence of events was calculated (24). The covariates were selected on the basis of biological plausibility and included age, gender, diabetes, and CVD. Statistical analyses were performed using SAS version 9.4 (SAS Campus Drive, Cary, NC, USA).

\section{RESULTS}

\section{S100A12 AND SRAGE LEVELS IN PD AND HD PATIENTS AND CONTROLS}

Characteristics of the 82 PD patients, control subjects $(n=$ $50)$ and HD patients $(n=190)$ are summarized in Table 1. Median S100A12 was 4.3 times higher, median SRAGE 2.5 times higher, and median ratio S100A12/sRAGE was 1.9 times

TABLE 1

Characteristics and Laboratory Variables of Control Subjects, PD Patients, and HD Patients

\begin{tabular}{|c|c|c|c|}
\hline & $\begin{array}{l}\text { Controls } \\
(n=50)\end{array}$ & $\begin{array}{c}\text { PD } \\
(n=82)\end{array}$ & $\begin{array}{c}\text { HD } \\
(n=190)\end{array}$ \\
\hline Age (years) ${ }^{\mathrm{a}}$ & $63(58-70)$ & $65(56-76)$ & $67(51-74)$ \\
\hline Males (\%) & $31(62 \%)$ & $57(70 \%)$ & $106(56 \%)$ \\
\hline Vintage (months) ${ }^{b}$ & - & $12(6-29)$ & $29(14-55)$ \\
\hline $\mathrm{DM}, n(\%)$ & $0(0 \%)$ & $20(24 \%)$ & $46(24 \%)$ \\
\hline CVD, $n(\%)$ & $0(0 \%)$ & $24(29 \%)$ & $121(64 \%)$ \\
\hline PVCD,$n(\%)$ & - & $23(28 \%)$ & $56(29 \%)$ \\
\hline $\operatorname{GFR}\left(\mathrm{mL} / \mathrm{min} / 1.73 \mathrm{~m}^{2}\right)^{\mathrm{a}}$ & $82(76-91)$ & $2.6(1.2-3.9)$ & - \\
\hline BMI $\left(\mathrm{kg} / \mathrm{m}^{2}\right)$ & $25.4 \pm 3.9$ & $25.5 \pm 3.9$ & $24.8 \pm 5.3$ \\
\hline FBMI $\left(\mathrm{kg} / \mathrm{m}^{2}\right)$ & $8.13 \pm 3.3$ & $8.4 \pm 2.9$ & $8.1 \pm 3.3$ \\
\hline $\operatorname{LBMI}\left(\mathrm{kg} / \mathrm{m}^{2}\right)$ & $16.5 \pm 2.1$ & $16.3 \pm 2.1$ & $16.6 \pm 2.7$ \\
\hline $\mathrm{SGA}>1(\%)$ & $2(4 \%)$ & $30(39 \%)$ & $89(47 \%)$ \\
\hline S-albumin (g/L) & $39.0 \pm 2.8$ & $31.4 \pm 4.5$ & $35.0 \pm 4.2$ \\
\hline S-creatinine $(\mu \mathrm{mol} / \mathrm{L})$ & $79 \pm 15$ & $725 \pm 175$ & $780 \pm 209$ \\
\hline Total cholesterol (mmol/L) & $5.2 \pm 0.8$ & $5.1 \pm 1.3$ & $4.3 \pm 0.9$ \\
\hline IL-6 $(\mathrm{pg} / \mathrm{mL})^{\mathrm{b}}$ & - & $6.4(3.9-9.6)$ & $8.5(4.8-15.0)$ \\
\hline $\operatorname{CRP}(\mathrm{mg} / \mathrm{L})^{b}$ & $1.2(0.6-2.6)$ & $4.1(1.4-9.8)$ & $6.4(2.5-19.5)$ \\
\hline CML $(\mu \mathrm{g} / \mathrm{mL}, n=59)^{\mathrm{b}}$ & - & $0.75(0.64-0.9)$ & - \\
\hline S100A12 (ng/mL) & $6.7(4.6-10.0)$ & $28.6(19.6-46.2)$ & $14.7(8.8-33.9)$ \\
\hline $\operatorname{sRAGE}(\mathrm{ng} / \mathrm{mL})^{\mathrm{b}}$ & $1.3(0.8-1.7)$ & $3.3(2.5-4.2)$ & $3.8(2.6-5.9)$ \\
\hline S100A12/sRAGE ratio ${ }^{b}$ & $5.2(4.0-8.4)$ & $9.9(5.5-6.9)$ & $4.1(1.8-9.9)$ \\
\hline
\end{tabular}

$\mathrm{PD}=$ peritoneal dialysis; $\mathrm{HD}=$ hemodialysis; $\mathrm{DM}=$ diabetes mellitus; $\mathrm{CVD}=$ cardiovascular disease; $\mathrm{PVCD}$ = peripheral or cerebrovascular disease; $\mathrm{GFR}=$ glomerular filtration rate; $\mathrm{BMI}=$ body mass index; $F B M I=$ fat body mass index; $L B M I=$ lean body mass index; $S G A>1=$ subjective global assessment score (indicating protein-energy wasting); IL-6= interleukin-6; CRP = C-reactive protein; CML= NE-(Carboxymethyl)lysine; sRAGE = soluble receptor of advanced glycation end-products; $\mathrm{SD}=$ standard deviation.

Data are expressed as a median (range), ${ }^{\mathrm{b}}$ median $\left(25^{\text {th }}\right.$ to $75^{\text {th }}$ percentile), or as mean \pm SD or $n(\%)$.

This single copy is for your personal, non-commercial use only. For permission to reprint multiple copies or to order presentation-ready 
higher in PD patients than in controls. Compared with the HD patients, median S100A12 was 1.9 times higher, median SRAGE lower by 14\%, and median S100A12/sRAGE 2.4 times higher in PD patients.

Most PD patients were high (25\%) or high-average (53\%) transporters while $22 \%$ were low $(3 \%)$ or low-average (19\%) transporters. Plasma S100A12 and sRAGE levels were not significantly different between the transport groups.

\section{PERIPHERAL OR CEREBROVASCULAR DISEASE AND S100A12 IN PD AND HD PATIENTS}

Signs or history of PCVD was present in $28 \%$ of PD patients and $30 \%$ of HD patients (Table 2 ). In PD patients, those with PCVD more often were women, had lower GFR and albumin, and had higher IL-6 and S100A12, while the difference in S100A12/sRAGE between the 2 groups was only borderline significant. Soluble RAGE, DM, or nutritional status did not differ between the 2 groups. In HD patients, age, CRP, and IL-6 were significantly higher in patients with PCVD compared with those without PCVD; however, S100A12, sRAGE, S100A12/ SRAGE, DM and nutritional status did not differ between PCVD and non-PCVD patients (data not shown).
UNIVARIATE AND MULTIVARIATE CORRELATIONS WITH S100A12 AND SRAGE LEVELS IN PD

Overall, S100A12 associated with CRP $(\rho=0.47 ; p<0.001)$, IL-6 $(\rho=0.38 ; p<0.001)$, and mA0PP $(\rho=0.26 ; p=0.02)$, and negatively with albumin $(\rho=-0.27 ; p<0.05)$, Kt/V $(\rho=-0.22 ; p=0.06)$, and GFR $(\rho=-0.22 ; p=0.07)$. Soluble RAGE levels associated negatively with BMI $(\rho=-0.37$; $p<0.001)$, FBMI $(\rho=-0.34 ; p<0.05)$, and LBMI $(\rho=-0.37$; $p<0.05)$.

Multivariate logistic regression analysis (Table 3 ) showed that PCVD associated mainly with high S100A12 (OR 3.52, $p=0.04)$.

\section{S100A12 0R SRAGE AND MORTALITY RISK IN PD PATIENTS}

After a mean follow-up period of 31 months, 23 PD patients died and 19 patients underwent kidney transplantation. Median S100A12 at baseline was higher in 23 non-survivors $(36[11-62] \mathrm{ng} / \mathrm{mL}, p<0.05)$ than in 59 survivors who remained on $\mathrm{PD}(n=40 ; 23[16-31] \mathrm{ng} / \mathrm{mL})$ or underwent renal transplantation $(n=19 ; 29[23-54] \mathrm{ng} / \mathrm{mL})$ while no such differences were found for sRAGE (Figure $1 \mathrm{~A}, \mathrm{~B}$ ).

TABLE 2

Clinical Characteristics and Laboratory Variables in 82 PD Patients Without and With Signs or History of Peripheral or Cerebrovascular Disease

\begin{tabular}{|c|c|c|c|}
\hline & $\begin{array}{c}\text { No PCVD } \\
(n=59)\end{array}$ & $\begin{array}{c}\text { PCVD } \\
(n=23)\end{array}$ & $P$ value \\
\hline Age (years) ${ }^{a}$ & $64(53-76)$ & $67(57-80)$ & 0.17 \\
\hline Males (\%) & $45(76 \%)$ & $12(52 \%)$ & 0.03 \\
\hline Vintage (months) ${ }^{\mathrm{a}}$ & $12(6-29)$ & $11(5-31)$ & 0.62 \\
\hline $\mathrm{DM}(\%)$ & $12(20 \%)$ & $8(35 \%)$ & 0.28 \\
\hline CVD $(\%)$ & $13(22 \%)$ & $11(48 \%)$ & 0.02 \\
\hline $\mathrm{GFR}^{\mathrm{a}}$ & $2.9(1.4-5.2)$ & $1.7(0.8-2.7)$ & 0.01 \\
\hline $\mathrm{Kt} / \mathrm{V}^{\mathrm{a}}$ & $2.5(1.8-2.5)$ & $2.2(1.9-2.4)$ & 0.99 \\
\hline BMI $\left(\mathrm{kg} / \mathrm{m}^{2}\right)$ & $25.8 \pm 4.0$ & $24.6 \pm 3.5$ & 0.22 \\
\hline FBMI $\left(\mathrm{kg} / \mathrm{m}^{2}\right)$ & $8.6 \pm 2.7$ & $8.1 \pm 3.2$ & 0.43 \\
\hline $\operatorname{LBMI}\left(\mathrm{kg} / \mathrm{m}^{2}\right)$ & $16.4 \pm 2.1$ & $16.1 \pm 2.2$ & 0.62 \\
\hline$S G A>1(\%)$ & $20(34 \%)$ & $10(43 \%)$ & 0.37 \\
\hline S-albumin $(\mathrm{g} / \mathrm{L})$ & $32.5 \pm 4.0$ & $28.4 \pm 4.5$ & 0.001 \\
\hline Total cholesterol (mmol/L) & $5.1 \pm 1.3$ & $5.1 \pm 1.2$ & 0.75 \\
\hline $\mathrm{IL}-6(\mathrm{pg} / \mathrm{mL})^{\mathrm{b}}$ & $5.8(3.4-9.1)$ & $8.4(4.9-13.6)$ & 0.03 \\
\hline $\mathrm{CRP}(\mathrm{mg} / \mathrm{L})^{\mathrm{b}}$ & $3.7(1.4-7.8)$ & $5.7(1.3-21.8)$ & 0.06 \\
\hline $\mathrm{mAOPP}(\mu \mathrm{mol} / \mathrm{L})^{\mathrm{b}}$ & $138(119-154)$ & 127 (107-147) & 0.24 \\
\hline $\mathrm{CML}(\mu \mathrm{g} / \mathrm{mL}, n=59)^{\mathrm{b}}$ & $0.74(0.62-0.90)$ & $0.80(0.70-0.93)$ & 0.36 \\
\hline $\mathrm{S} 100 \mathrm{~A} 12(\mathrm{ng} / \mathrm{ml})^{\mathrm{b}}$ & $25.3(16.9-39.4)$ & $37.0(24.9-57.1)$ & 0.03 \\
\hline $\operatorname{sRAGE}(\mathrm{ng} / \mathrm{mL})^{b}$ & $3.3(2.4-4.3)$ & $3.3(2.8-3.9)$ & 0.70 \\
\hline S100A12/sRAGE ratio ${ }^{b}$ & $8.7(4.7-16.6)$ & $11.9(8.2-22.2)$ & 0.05 \\
\hline
\end{tabular}

$\mathrm{PD}=$ peritoneal dialysis; $\mathrm{PCVD}=$ peripheral or cerebrovascular disease; $\mathrm{DM}=$ diabetes mellitus; $\mathrm{CVD}=$ cardiovascular disease; $\mathrm{GFR}=\mathrm{glomerular}$ filtration rate; $B M I=$ body mass index; $F B M I=$ fat body mass index; $L B M I=$ lean body mass index; $S G A>1$ = subjective global assessment score (indicating protein-energy wasting); $\mathrm{IL}-6=$ interleukin- $6 ; \mathrm{CRP}=\mathrm{C}$-reactive protein; $\mathrm{mAOPP}=$ modified advanced oxidation protein product; $\mathrm{CML}=$ $\mathrm{N} \varepsilon$-(Carboxymethyl)lysine; sRAGE = soluble receptor of advanced glycation end-products; SD = standard deviation.

Data are expressed as a median (range), ${ }^{\text {b }}$ median $\left(25^{\text {th }}\right.$ to $75^{\text {th }}$ percentile), or as mean \pm SD, or $n(\%)$.

Significant $p$ values are indicated in bold. 
TABLE 3

Odds Ratios and 95\% Confidence Intervals for the Presence of Peripheral and Cerebrovascular Disease in 82 PD Patients

\begin{tabular}{lcrr}
\hline $\begin{array}{c}\text { Peripheral and } \\
\text { Cerebrovascular Disease }\end{array}$ & $\begin{array}{c}\text { Odds ratio } \\
(95 \% \mathrm{CI})\end{array}$ & $\mathrm{z}$ & SE \\
\hline Sex, female & $0.35(0.11-1.16)$ & 0.21 & 1.72 \\
Albumin, $>35 \mathrm{~g} / \mathrm{L}$ & $1.36(0.22-8.23)$ & 1.25 & 0.09 \\
SGA, well-nourished & $1.53(0.49-4.79)$ & 0.89 & 0.73 \\
SRAGE, $>3.3 \mathrm{ng} / \mathrm{mL}$ & $2.23(0.70-7.05)$ & 1.31 & 0.47 \\
S100A12, $>28.6 \mathrm{ng} / \mathrm{mL}$ & $\mathbf{3 . 5 2 ( 1 . 0 9 - 1 1 . 4 1 )}$ & 2.11 & 0.17 \\
\end{tabular}

$\mathrm{PD}=$ peritoneal dialysis; $\mathrm{CI}=$ confidence interval; $\mathrm{SE}=$ standard error; $\mathrm{SGA}=$ subjective global assessment; $\mathrm{SRAGE}=$ soluble receptor of advanced glycation end-products.

Pseudo $r^{2}=0.11$

Significant $p$ values are indicated in bold.
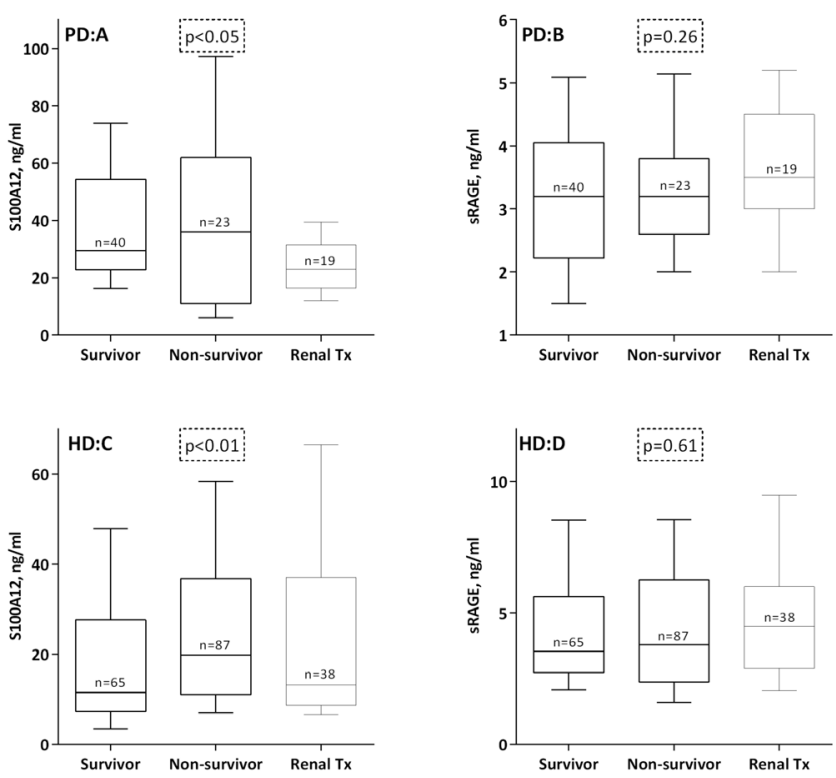

Figure 1 - Baseline plasma concentration of S100A12 (A,C) and sRAGE $(B, D)$ in survivors, non-survivors, and patients who underwent renal transplantation (Renal Tx) in PD and HD patients. Differences were assessed by Kruskal Wallis rank test. $\mathrm{SRAGE}=$ soluble receptor of advanced glycation end-products; $P D=$ peritoneal dialysis; $H D=$ hemodialysis.

A competing risk Cox regression model was used to analyze mortality risk associated with increased levels of $\mathrm{S} 100 \mathrm{~A} 12$ and SRAGE, taking into account kidney transplantation and adjusting for age, gender, and presence of DM and CVD. This analysis showed that the highest tertile of S100A12 versus the 2 other tertiles associated with increased mortality (Figure $2 \mathrm{~A}$ ). No such associations were found for sRAGE or S100A12/sRAGE ratio. In addition to high S100A12, presence of CVD was also a significant predictor of mortality in PD patients (Table 4).

\section{S100A12 OR SRAGE AND MORTALITY RISK IN HD PATIENTS}

After a mean follow-up period of 29 months, $87 \mathrm{HD}$ patients died and 38 patients underwent kidney transplantation.
Median S100A12 at baseline was higher in 87 non-survivors (36 $[11-62] \mathrm{ng} / \mathrm{mL}, p<0.01)$ than in 103 survivors who remained on $\mathrm{HD}(n=65 ; 23[16-31] \mathrm{ng} / \mathrm{mL})$ or who underwent renal transplantation $(n=38 ; 29[23-54] \mathrm{ng} / \mathrm{mL})$ while no such differences were found for sRAGE or S100A12/sRAGE in HD patients (Figure $1 \mathrm{C}, \mathrm{D}$ ).

Similar to the case for PD patients, the competing risk Cox regression model, adjusting for age, gender, DM, and CVD, showed that the highest tertile versus middle and lowest tertiles of S100A12 associated with increased mortality (Figure 2 B) while no such associations were found for sRAGE or S100A12/sRAGE ratio. In addition to high S100A12, high age ( $>65$ years) was also a significant predictor of mortality in HD patients (Table 4).

\section{DISCUSSION}

To the best of our knowledge, this is the first study on associations of circulating S100A12 and sRAGE with mortality risk and nutritional status in PD patients. We report the novel findings that high $\mathrm{S} 100 \mathrm{~A} 12$ associates with mortality in prevalent PD patients-similar to observations in CKD stage- 5 patients starting on dialysis (17) and prevalent HD patients (18) -and that S100A12 associates with biomarkers of inflammation and presence of $P C V D$, suggesting that the mortality-predictive role of S100A12 is linked to vascular disease involving inflammatory mediators.

Whereas SRAGE-in contrast to S100A12 and in agreement with the previous 2 studies-was not associated with inflammation, comorbidity, or mortality, we report the novel and intriguing finding that SRAGE in PD patients was inversely related to indices of body mass, i.e., BMI, FBMI, and LBMI. Levels of sRAGE are generally lower in patients with chronic inflammatory conditions, and plasma endogenous RAGE was reported to be inversely correlated with components of the metabolic syndrome including obesity (8). Furthermore, compared with non-obese healthy controls, patients with morbid obesity have been reported to have significantly lower sRAGE levels that increased significantly after weight loss induced by bariatric surgery. These observations suggesting possible

This single copy is for your personal, non-commercial use only.

For permission to reprint multiple copies or to order presentation-ready

copies for distribution, contact Multimed Inc. at marketing@multi-med.com 


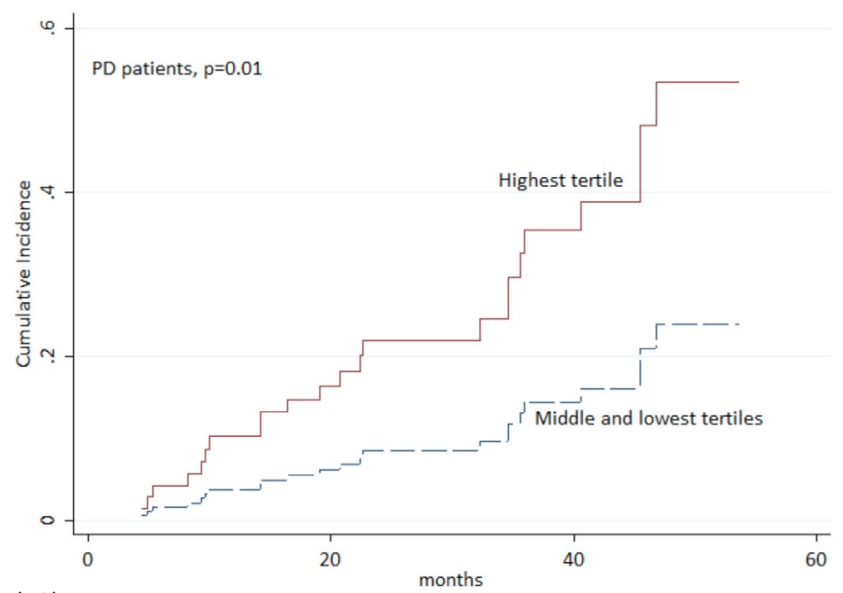

$(2 \mathrm{~A})$

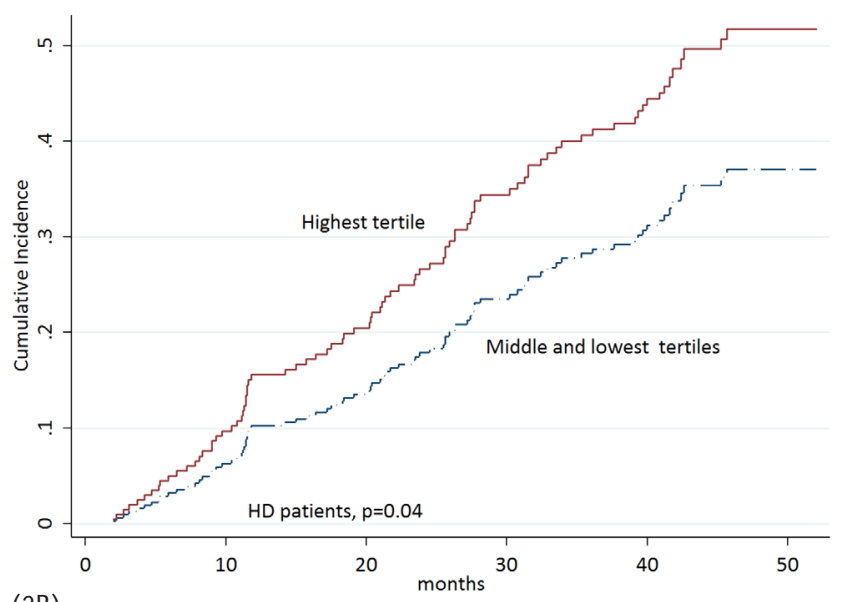

(2B)

Figure 2 - Relation between S100A12 cumulative incidence rates for the competing end-points of renal transplantation or death in patients with highest tertile of S100A12 versus the lower tertiles of S100A12 in PD (Fig. 2A) and HD (Fig. 2B) patients. These incidence rates are adjusted for age, gender, and presence of comorbid conditions, diabetes, and cardio-vascular disease. $\mathrm{PD}=$ peritoneal dialysis; $\mathrm{HD}=$ hemodialysis.

TABLE 4

Sub-Hazard Ratio and 95\% Confidence Intervals for All-Cause Mortality Risk in 82 PD and 190 HD Patients

\begin{tabular}{lccc}
\hline & PD SHR (95\% CI) & $P$ & HD SHR (95\% CI) \\
\hline S100A12, highest tertile vs other & $2.91(1.01-1.16)$ & $\mathbf{0 . 0 1}$ & $\mathbf{1 . 5 7 ( 1 . 2 0 - 7 . 0 2 )}$ \\
Sex, female & $0.99(0.38-2.55)$ & 0.99 & $1.36(0.87-2.10)$ \\
Age $<$ 45 yrs vs 45-65 yrs & $1.22(0.12-12.22)$ & 0.86 & 0.17 \\
Age $<$ 45 yrs vs $>65$ yrs & $2.61(0.25-26.46)$ & 0.41 & 0.47 \\
CVD, presence & $3.11(1.27-7.61)$ & $\mathbf{0 . 0 1}$ & $\mathbf{9 . 0 2 ( 2 . 2 4 - 3 6 . 3 2 )}$ \\
DM, presence & $1.17(0.65-2.10)$ & 0.59 & $1.51(0.93-2.46)$ \\
\end{tabular}

$\mathrm{PD}=$ peritoneal dialysis; $\mathrm{HD}=$ hemodialysis; $\mathrm{SHR}=$ sub-hazard ratio; $\mathrm{CI}=$ confidence interval; $\mathrm{CVD}=$ cardiovascular disease; $\mathrm{DM}=$ diabetes mellitus. Significant $p$ values are indicated in bold.

links between high fat mass and low levels of the putatively protective sRAGE should be further explored in CKD patients.

S100A12, sRAGE, and S100A12/sRAGE were all markedly elevated in our PD patients. In uremia, increased formation and accumulation of AGEs result in up-regulation of RAGE linked to interstitial peritoneal fibrosis and vascular sclerosis (25), and exposure to high glucose PD fluids may further contribute to such changes (26). Not surprisingly, sRAGE and S100A12 accumulate in PD patients (15-17), as shown also in the current study, and hyperglycemia-induced reactive oxygen species may further increase expression of RAGE and RAGE-ligands (27). As we found an inverse relation of $S 100 A 12$, but not of SRAGE, with solute removal indices (GFR and KT/V), this may suggest that S100A12 is removed by the kidneys or that better metabolic control of uremia linked to residual renal function or dialytic removal of toxins result in lower plasma S100A12.

While the median S100A12 concentration was 1.9 times higher and the median S100A12/sRAGE ratio 2.4 times higher in PD patients than in HD patients, this difference was not due to $P D$ patients being more inflamed than the HD patients; median CRP and IL-6 levels were higher in HD than in PD patients (Table 1). It is possible that the difference in plasma
S100A12 levels between HD and PD patients could be due to inherent differences between the 2 dialysis modalities such as the aforementioned stimulation of the AGE-RAGE system by glucose-based dialysis solutions, but it is likely that differences in patient characteristics or medications may also play a role. It is not known to what extent S100A12 is removed by PD or HD but some removal is likely to occur, considering that the molecular weight of $\mathrm{S} 100 \mathrm{~A} 12$ is similar to that of $\beta 2$-microglobulin. Other factors that potentially could influence the plasma S100A12 level in CKD remain unclear; the metabolism and excretion of S100A12 in mammals has, to the best of our knowledge, not been reported.

In the current study, plasma S100A12 associated with inflammatory mediators and was an independent determinant of PCVD and mortality, suggesting that vascular disease linked to RAGE/S100A12-mediated inflammation contributed to worse clinical outcomes. Whereas in HD patients, S100A12 associates with carotid intima media thickness (IMT) (6), clinical signs of CVD (18), and vascular calcification (14), sRAGE was reported to be inversely associated with IMT and plaque number in CKD patients (28), in agreement with the hypothesis that sRAGE inhibits RAGE-mediated inflammation, 
and therefore may protect against inflammation-mediated vascular changes. However, in the current study sRAGE did not associate (inversely) with inflammation or PCVD and a protective effect of sRAGE was not observed. A possible reason could be that the elevation of S100A12 exceeded that of sRAGE: the ratio of S100A12/sRAGE in PD patients was about twice as high as the ratio in controls and HD patients (Table 1), and the ratio was also significantly higher in patients with PCVD than in non-PCVD patients (Table 2). This may suggest that the putative harmful effect of high S100A12 was not sufficiently counteracted by a corresponding rise in SRAGE. Thus, interactions of AGEs and other RAGE-ligands including S100A12 (25) resulting in downstream activation of nuclear factor- $K B$, up-regulation of adhesion molecules in vascular endothelial cells, and enhanced migration and activation of monocytes/ macrophages (29) may have prevailed in our patients leading to vascular changes.

A number of limitations of the present study should be acknowledged. First, due to the cross-sectional design, we cannot draw any conclusions regarding causality of observed associations or to what extent levels of S100A12 and sRAGE are affected by dialysis modality. Secondly, we did not analyze other relevant markers in the AGE-RAGE signaling pathway. Third, the biochemical analyses were performed only once at baseline. Our study should therefore be regarded as hypothesis-generating in nature. Mechanistic studies as well as larger studies with longer follow-up are warranted to explore the potential importance of S100A12 and sRAGE for vascular disease and mortality in PD patients and other groups of CKD patients.

In summary, plasma S100A12 and sRAGE concentrations, as well as the S100A12/sRAGE ratio, are markedly elevated in PD patients. Plasma SRAGE, which is thought to be antiinflammatory and protective against atherosclerotic CVD, was inversely related to BMIs but did not associate with inflammation, presence of PCVD, or clinical outcome. Plasma S100A12 associated with inflammation, presence of PCVD, and increased mortality suggesting that S100A12 may identify PD patients at risk for vascular disease and increased mortality.

\section{ACKNOWLEDGMENTS}

We are grateful to the patients and control subjects participating in the study. We thank Åsa Lindé and Annika Nilsson, Anki Emmoth, and Ulrika Jensen for collection of samples, and Ann-Christin BragforsHelin and Monica Eriksson for laboratory analyses. We acknowledge the generous grants from Amgen for sponsoring the current study. This study was supported by grants also from the Swedish Medical Research Council, Osterman's, Martin Rind's and Westman's Foundations, and by a grant from Yamaguchi University, Ube, Yamaguchi, Japan. Baxter Novum is the result of a grant from Baxter Healthcare Corporation to the Karolinska Institutet.

\section{DISCLOSURES}

$B L$ and $A M$ are affiliated with Baxter Healthcare Corporation. PS is a previous member of the scientific advisory board of Gambro AB. None of the other authors declare any conflicts of interest.

\section{REFERENCES}

1. Park SH, Stenvinkel P, Lindholm B. Cardiovascular biomarkers in chronic kidney disease. J Ren Nutr 2012; 22(1):120-7.

2. Stenvinkel P, Carrero J, Axelsson J, Lindholm B, Heimbürger 0, Massy Z. Emerging biomarkers for evaluating cardiovascular risk in the chronic kidney disease patient: how do new pieces fit into the uremic puzzle? Clin J Am Soc Nephrol 2008; 3(2):505-21.

3. Leurs $P$, Lindholm B. The AGE-RAGE pathway and its relation to cardiovascular disease in patients with chronic kidney disease. Arch Med Res 2013; 44(8):601-10.

4. Vlassara H. The AGE-receptor in the pathogenesis of diabetic complications. Diabetes Metab Res Rev 2001; 17(6):436-43.

5. Selvin E, Halushka MK, Rawlings AM, Hoogeveen RC, Ballantyne CM, Coresh $\mathrm{J}$, et al. sRAGE and risk of diabetes, cardiovascular disease, and death. Diabetes 2013; 62(6):2116-21.

6. Mori Y, Kosaki A, Kishimoto N, Kimura T, Iida K, Fukui M, et al. Increased plasma S100A12 (EN-RAGE) levels in hemodialysis patients with atherosclerosis. Am J Nephrol 2009; 29(1):18-24.

7. Bucciarelli LG, Wendt T, Qu W, Lu Y, Lalla E, Rong LL, et al. RAGE blockade stabilizes established atherosclerosis in diabetic apolipoprotein E-null mice. Circulation 2002; 106(22):2827-35.

8. Koyama H, Shoji T, Yokoyama H, Motoyama K, Mori K, Fukumoto S, et al. Plasma level of endogenous secretory RAGE is associated with components of the metabolic syndrome and atherosclerosis. Arterioscler Thromb Vasc Biol 2005; 25(12):2587-93.

9. Basta G, Sironi AM, Lazzerini G, Del Turco S, Buzzigoli E, Casolaro A, et al. Circulating soluble receptor for advanced glycation end products is inversely associated with glycemic control and S100A12 protein. J Clin Endocrinol Metab 2006; 91(11):4628-34.

10. Zakiyanov 0, Kalousova M, Kriha V, Zima T, Tesar̆ V. Serum S100A12 (EN-RAGE) levels in patients with decreased renal function and subclinical chronic inflammatory disease. Kidney Blood Press Res 2011; 34(6):457-64.

11. Kalousová M, Kubĕna AA, Benáková H, Dusilová-Sulková S, Tesar̆ V, Zima T. EN-RAGE (extracellular newly identified receptor for advanced glycation end-products binding protein) and mortality of long-term hemodialysis patients: a prospective observational cohort study. Clin Biochem 2012; 45(7-8):556-60.

12. Gohda T, Tanimoto M, Moon JY, Gotoh H, Aoki T, Matsumoto M, et al. Increased serum endogenous secretory receptor for advanced glycation end-product (esRAGE) levels in type 2 diabetic patients with decreased renal function. Diabetes Res Clin Pract 2008;81(2):196-201.

13. Suzuki S, TakeishiY, Niizeki T, Koyama Y, Kitahara T, Sasaki T, et al. Pentraxin 3 , a new marker for vascular inflammation, predicts adverse clinical outcomes in patients with heart failure. Am Heart J 2008; 155(1):75-81.

14. Wang YN, Sun Y, Wang Y, Jia YL. Serum S100A12 and progression of coronary artery calcification over 4 years in hemodialysis patients. Am J Nephrol 2015;42(1):4-13.

15. Kim JK, Park S, Lee MJ, Song YR, Han SH, Kim SG, et al. Plasma levels of soluble receptor for advanced glycation end products (SRAGE) and proinflammatory ligand for RAGE (EN-RAGE) are associated with carotid atherosclerosis in patients with peritoneal dialysis. Atherosclerosis 2012; 220(1):208-14.

16. Uchiyama-Tanaka Y, Mori Y, Kosaki A, Kimura T, Moriishi M, Kawanishi $\mathrm{H}$, et al. Plasma S100A12 concentrations in peritoneal dialysis patients and subclinical chronic inflammatory disease. Ther Apher Dial 2008; 12(1):28-32.

17. Isoyama N, Leurs $P$, Qureshi AR, Bruchfeld A, Anderstam B, Heimburger 0 , et al. Plasma S100A12 and soluble receptor of advanced glycation end product levels and mortality in chronic kidney disease stage 5 patients. Nephrol Dial Transplant 2015; 30(1):84-91.

18. Nakashima A, Carrero JJ, Qureshi AR, Miyamoto T, Anderstam B, Bárány $P$, et al. Effect of circulating soluble receptor for advanced glycation end products (sRAGE) and the proinflammatory RAGE ligand (EN-RAGE, S100A12) on mortality in hemodialysis patients. Clin J Am Soc Nephrol 2010; 5(12):2213-9.

19. Durnin JV, Womersley J. Body fat assessed from total body density and

This single copy is for your personal, non-commercial use only.

For permission to reprint multiple copies or to order presentation-ready

copies for distribution, contact Multimed Inc. at marketing@multi-med.com 
its estimation from skinfold thickness: measurements on 481 men and women aged from 16 to 72 years. Br J Nutr 1974; 32(1):77-97.

20. Kyle UG, Schutz Y, Dupertuis YM, Pichard C. Body composition interpretation. Contributions of the fat-free mass index and the body fat mass index. Nutrition 2003; 19(7-8):597-604

21. Qureshi AR, Alvestrand A, Danielsson A, Divino-Filho JC, Gutierrez $A$, Lindholm B, et al. Factors predicting malnutrition in hemodialysis patients: a cross-sectional study. Kidney Int 1998; 53(3):773-82.

22. Davies SJ, Phillips L, Naish PF, Russell GI. Quantifying comorbidity in peritoneal dialysis patients and its relationship to other predictors of survival. Nephrol Dial Transplant 2002; 17(6):1085-92.

23. Xu H, Watanabe M, Qureshi A, Heimbürger 0 , Bárány P, Anderstam B, et al. Oxidative DNA damage and mortality in hemodialysis and peritoneal dialysis patients. Perit Dial Int 2014; 35(2):206-15.

24. Fine J, Gray R. A proportional hazards model for the subdistribution of a competing risk. J Am Stat Assoc 1999; 94:496-509.

25. De Vriese AS, Tilton RG, Mortier S, Lameire NH. Myofibroblast transdifferentiation of mesothelial cells is mediated by RAGE and contributes to peritoneal fibrosis in uraemia. Nephrol Dial Transplant 2006; 21(9):2549-55.

26. Müller-Krebs S, Kihm LP, Zeier B, Gross ML, Wieslander A, Haug U, et al. Glucose degradation products result in cardiovascular toxicity in a rat model of renal failure. Perit Dial Int 2010; 30(1):35-40.

27. Yao D, Brownlee M. Hyperglycemia-induced reactive oxygen species increase expression of the receptor for advanced glycation end products (RAGE) and RAGE ligands. Diabetes 2010; 59(1):249-55.

28. Basta G, Leonardis D, Mallamaci F, Cutrupi S, Pizzini P, Gaetano L, et al. Circulating soluble receptor of advanced glycation end product inversely correlates with atherosclerosis in patients with chronic kidney disease. Kidney Int 2010; 77(3):225-31.

29. Bakkaloglu SA, Saygili A, Sever L, Noyan A, Akman S, Ekim M, etal. Assessment of cardiovascular risk in paediatric peritoneal dialysis patients: a Turkish Pediatric Peritoneal Dialysis Study Group (TUPEPD) report. Nephrol Dial Transplant 2009; 24(11):3525-32. 